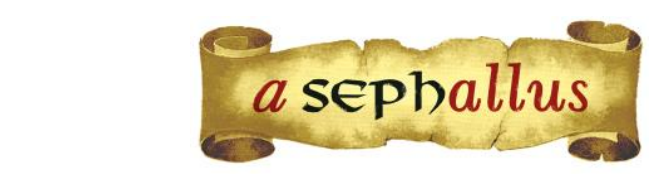

Revista aSEPHallus de Orientação Lacaniana

Núcleo Sephora de Pesquisa sobre o Moderno e o Contemporâneo

ISSN 1809 - 709 X

\title{
Psicanálise selvagem ou perversão transitória?
}

José Maurício Teixeira Loures

Psicanalista, graduado em Psicologia pela Universidade Veiga de Almeida (Rio de Janeiro/RJ). Doutorando e Mestre em Psicanálise, Saúde e Sociedade (UVA, Rio de Janeiro/RJ). Docente do curso de pós-graduação lato sensu em Teoria Psicanalítica e Prática Clínico-Institucional (UVA, Rio de Janeiro/RJ). Editor Adjunto da Revista Trivium - estudos interdisciplinares. Membro do corpo editorial da revista Stylete Lacaniano. Coordena o Seminário "A interpretação em Freud" na Escola de Psicanálise dos Fóruns do Campo Lacaniano - Região dos Lagos (Cabo Frio/RJ). E-mail: mauricio.mauricio@gmail.com

Maria Helena Martinho

Doutora e Mestre pelo Programa de Pós-Graduação em Psicanálise do Instituto de Psicologia da Universidade do Estado do Rio de Janeiro/UERJ (Rio de Janeiro/RJ). Docente e Supervisora Clínica do Curso de Especialização em Psicologia Clínica da Pontifícia Universidade Católica do Rio de Janeiro (Rio de Janeiro/RJ). Psicanalista Membro da Escola de Psicanálise dos Fóruns do Campo Lacaniano/EPFCL-Brasil e do Colegiado de Formações Clínicas do Campo Lacaniano/EPFCL(Rio de Janeiro/RJ). E-mail: mhmartinho@yahoo.com.br

Resumo: Este artigo visa interrogar a direção do tratamento em um caso clínico apresentado pela psicanalista francesa Ruth Lebovici. O caso foi publicado originalmente em 1956 e intitula-se "Perversão sexual transitória no decorrer de um tratamento psicanalítico". Esse estudo evidencia os efeitos das interpretações selvagens da analista. As proposições de Freud e de Lacan sobre a interpretação e, mais especificamente, os comentários de Lacan sobre o caso, elucidam os deslizamentos sofridos na técnica psicanalítica.

Palavras-Chave: interpretação psicanalítica; psicanálise selvagem; direção do tratamento; técnica psicanalítica.

Psychanalyse sauvage ou perversion transitoire?: Cet article vise à remettre en question la direction du traitement dans un cas clinique présenté par la psychanalyste française Ruth Lebovici. L'affaire a été publiée en 1956 et s'intitule "Perversion sexuelle transitoire au cours d'un traitement psychanalytique". Cette étude met en évidence les effets des interprétations sauvages de l'analyste. Les propositions de Freud et de Lacan sur l'interprétation et, plus précisément, les commentaires de Lacan sur l'affaire, élucident les glissements subis par la technique psychanalytique.

Mots-clés: interprétation psychanalytique; psychanalyse sauvage; direction du traitement; technique psychanalytique.

Wild psychoanalysis or transitional perversion?: This article aims at the question of the direction of treatment in a clinical case presented by the French psychoanalyst Ruth Lebovici. The case was originally published in 1956 and is entitled "Transient Sexual Perversion in the course of a psychoanalytic treatment." This study highlights the effects of the analyst's wild interpretations. The propositions of Freud and Lacan on the interpretation and, more specifically, the comments of Lacan on the case, elucidate the slides suffered in the psychoanalytical technique.

Keywords: psychoanalytic interpretation; wild psychoanalysis; treatment direction; psychoanalytic technique. 


\section{Psicanálise selvagem ou perversão transitória?}

José Maurício Teixeira Loures \& Maria Helena Martinho

\section{Introdução}

Em 1900, Freud surpreendeu a humanidade com seu estudo sobre os sonhos, em que estabeleceu que os sonhos possuem sentido e que, a partir de sua interpretação - empreendida pelo próprio sonhador -, é possível se chegar à expressão mais fundamental do desejo: a sexualidade, sempre infantil. Legitimou, assim, o sonho como uma linguagem, em cujas mensagens cifradas, destorcidas pelos mecanismos de condensação e de deslocamento, podem ser interpretadas pelo método da associação livre. Foi com a publicação da Traumdeutung que Freud formalizou diretrizes sobre a interpretação psicanalítica não só no que se refere aos sonhos, mas, também, as outras formações do inconciente.

Dez anos depois, Freud publicou um texto intitulado "Psicanálise selvagem", no qual advertia os psicanalistas sobre os deslizamentos sofridos na técnica psicanalítica. Enfatizou os danos que uma análise pode provocar quando o analista se apropria de um saber sobre o analisante, ressaltando que a intervenção do analista requer um período longo de contato com o paciente - e, por isso, as tentativas de surpreender o sujeito nas primeiras entrevistas, desvelando seus segredos, é tecnicamente inadmissível.

Neste artigo, nos propomos a interrogar a direção do tratamento em um caso atendido pela psicanalista Ruth Lebovici, publicado originalmente em 1956, intitulado "Perversão sexual transitória no decorrer de um tratamento psicanalítico". O caso foi comentado por Lacan em diversos momentos do seu ensino: O Seminário, livro 4: a relação de objeto (1956-1957/1995), 0 Seminário, livro 5: as formações do inconsciente (1957-1958/1999), O Seminário, livro 6: o desejo e sua interpretação (1958-1959/2016), e no texto publicado em Escritos: "A direção do tratamento e os princípios do seu poder" (1958/1998). Verificamos, com Lacan, que as interpretações de Lebovici se afastam dos fundamentos psicanalíticos e configuram essa prática que Freud chamou de "psicanálise selvagem".

\section{0 caso Yes}

Yves, um rapaz de vinte e três anos, piloto da marinha mercante, chegou à análise com o seguinte sintoma: evita sair de casa com medo de que as pessoas o achem ridículo por ser alto demais. Quando buscou análise, o rapaz era totalmente inativo e evitava saídas durante o dia por causa do seu tamanho. Logo após as primeiras entrevistas, Lebovici concluiu que Yves sofria de uma fobia, com o argumento de que "o mecanismo essencial que parecia orientar a formação desse sintoma era o deslocamento da angústia, e a tendência a evitar a situação fobogênica" (Lebovici, 1956/1999, p. 164).

Em uma sessão, Yves relatou o seguinte sonho: "Um homem, vestido com uma armadura, 
o ataca por trás, com uma espécie de máscara de gás, lembrando uma bomba de inseticida e que seria capaz de sufocá-lo" (Lebovici, 1956/1999, p. 167). Lebovici interpretou, ela própria, o sonho do seu paciente e lhe disse que o homem de armadura é a sua mãe fálica. Além disso, sugeriu uma associação entre o homem, que o sufocaria no escuro, e um possível sentimento de sufocamento durante as sessões, como se ele temesse a analista do mesmo modo que temia esse homem. Lebovici concluiu que Yves tinha medo das mulheres fálicas, particularmente, de sua mãe - e dela própria, a analista.

Em outra sessão, Yves relata mais dois sonhos: "No salão de um café, [...] encontra uma mulher grande, afasta suas coxas e vê que ela tem três pênis. Ele chupa e acaricia um dos pênis e acorda com uma ejaculação." (Lebovici, 1956/1999, p. 167). Na sequência, sonha que tem relações sexuais com a sua mãe. Na concepção da analista, o primeiro sonho e mais estes dois, que fazem série, comprovam a sua teoria da mãe fálica, que está na base de suas interpretações.

Yves ficou em análise durante cinco anos. No terceiro ano de análise, ele desenvolveu, segundo a analista, uma fantasia perversa: em um primeiro momento, o rapaz se imaginava urinando e sendo visto por uma mulher, excitada, que queria fazer sexo com ele. Em seguida, houve uma inversão dessa fantasia, passou a fantasiar que via uma mulher urinando e se masturbando. Em um terceiro tempo, alega Lebovici, ele concretizou sua fantasia em ato, quando começou a se masturbar no banheiro de um cinema, imaginando que espiava mulheres urinando. Posteriormente, descobriu uma cabine do banheiro feminino, onde passou a olhar, através de um furo na divisória, as mulheres da cabine ao lado e se masturbava ao vê-las urinar. Segundo a analista, o voyeurismo estaria relacionado a uma "inversão da exibição implicada em sua fobia" medo de ser visto / desejo de ver - e considera que Yves apresentou uma "uma perversão sexual transitória".

Lebovici relata que, em uma determinada sessão, Yves diz que seu tratamento só terminaria quando ele tivesse relações sexuais com a sua analista. Ela maneja o dito de seu paciente com a seguinte pontuação: "você está brincando de se amedrontar com um acontecimento que sabe que nunca irá ocorrer." (Lebovici, 1956/1999, p. 169). E explica a razão de sua intervenção: evitar um jogo intelectual que julgava perceber em Yves e que provavelmente teria chegado a ele como uma interdição de contato, "não apenas no plano genital, mas também no plano pré-genital e agressivo, ao qual ele estava fixado" (Lebovici, 1956/1999, p. 177).

Para Lebovici, sua intervenção teria desencadeado no seu paciente uma propensão à realização fora da transferência, já que, em seguida, Yves começou a se masturbar no cinema.

Yves traz outro sonho:

[...] quer propor à vendedora de peixes, amiga de seus pais, que tenha relações sexuais com ele, mas é impedido quando vê a empregada desta última. No curso de suas associações de ideias, conta-nos que havia visto 
a vendedora de peixes urinar [...]. Ele diz que tinha ficado apaixonado pela empregada do sonho, mas teve medo de seu marido. (Lebovici, 1956/1999, p. 168)

Lebovici, mais uma vez, interpreta, ela própria, o sonho do paciente, e destaca dois pontos: considera que seria menos perigoso para Yves olhar do que chegar de fato ao ato sexual, exercendo sua força viril - porque, caso ele exercesse a sua força viril, machucaria a mulher; ou ainda, ficaria amedrontado com a reação do marido traído (Lebovici, 1956/1999).

As idas de Yves ao cinema para se masturbar sessaram após a intervenção de um "lanterninha", que o pegou espiando e o repreendeu enfaticamente. Lebovici relata que, ao final do tratamento, Yves não sofria mais de fobias e não ficava mais tão incomodado com sua altura. Ela assevera: "Yves encontrou na psicanálise a possibilidade de um contato humano que ele jamais experimentara, por causa das defesas contra [suas] pulsões" (Lebovici, 1956/1999, p. 179). Para a analista, o sucesso da análise estaria relacionado à uma "mobilização dessas defesas e à uma evolução para uma genitalização que ele parece ter alcançado" (Lebovici, 1956/1999, p. 179).

\section{Com Lacan, algumas considerações sobre o caso}

Lacan nos convoca a pensar sobre as circunstâncias em que o sintoma do paciente emerge. Ele interroga se isso que a analista nomeou de "perversão transitória" não é, na verdade, consequência de uma análise selvagem. O que teria levado Ruth Lebovici a fazer comunicações intrusivas, provocando efeitos nefastos em seu analisante? Para respondermos a esta pergunta, cabe, inicialmente, apontarmos a confusão conceitual feita pela analista entre objeto fóbico e objeto fetiche.

Em O Seminário, livro 4: A relação de objeto (1956-1957), Lacan já havia verificado que tanto o objeto fóbico quanto o objeto fetiche desempenham uma função de proteção contra a angústia. Mas, embora o objeto fóbico e o objeto fetiche estejam centrados "no mesmo fundo de angústia fundamental, sobre a qual um e outro seriam convocados como uma medida de proteção ou de garantia da parte do sujeito" (Lacan, 1956-1957/1995, p. 22), há diferenças entre a função de uma fobia e a de um fetiche.

A fobia é, em suma, uma estratégia através da qual o sujeito tenta defender-se do gozo do Outro pelo significante, que recobre o objeto que causa o desejo e lhe dá um valor de causa de medo. Quando o significante Nome-do-Pai não responde de forma suficiente para barrar o não simbolizável do desejo da mãe, o sujeito passa a utilizar um significante metafórico contra a ameaça de devoramento do Outro. Esse significante se constitui como um objeto fóbico, que faz suplência ao Nome-do-Pai, operador lógico da castração, protegendo o sujeito da angústia de castração.

Ao contrário, no fetichismo, o fetiche, enquanto símbolo, também vela o objeto, mas não 
Ihe dá esse valor repelente; muito pelo contrário, fixa o sujeito, agarra-o. O fetiche é um objeto que o sujeito entrevê no intervalo entre dois significantes, isto é, no corte que o significante opera no real e que ele próprio sutura, desmentindo a falta.

Em síntese, o abismo que se abre diante da falta de pênis da mãe leva a duas respostas: uma consiste em proteger-se com uma fobia e, a outra, a proteger-se erigindo um fetiche, um substituto do pênis que falta à mãe. O significante fóbico e o objeto fetiche designam, então, posições distintas do sujeito frente à castração, causa de horror para o primeiro e causa de gozo para o último.

O caso Yves foi apresentado em 1956, treze anos antes de Lacan ter conceituado a fobia como uma "placa giratória". Até 1968/69, Lacan, seguindo a trilha de Freud, considerava a fobia como um tipo clínico da neurose, mas, em O Seminário, livro 16: De um Outro ao outro (19681969), ele pôde verificar que a fobia não é uma entidade clínica, mas uma "placa giratória" que aponta para a escolha, sempre forçada, do caminho a ser tomado pelo sujeito. Em outras palavras, o objeto fóbico e o objeto fetiche são duas portas de entrada em duas estruturas clínicas, respectivamente, neurose e perversão.

Ruth Lebovici não pôde se servir dos ensinamentos de Lacan na condução e construção do seu caso clínico. Embora a analista tenha feito um diagnóstico de fobia de maneira apurada, não levou em consideração o que sonho de Yves de fato revelava: a bomba de inseticida é um objeto fóbico, uma "representação cômica e característica do aparelho fálico como destruidor" (Lacan, 1957-1958/1999, p. 444) -, um "substituto maravilhosamente ilustrado de uma imagem paterna absolutamente carente" (Lacan, 1956-1957/1995, p. 88). Para Lacan - ao contrário do que propõe Lebovici, com a sua hipótese da "mãe fálica" -, Yves teria feito surgir ali a imagem necessária e faltante do pai, "na medida em que este último é exigido para a estabilização do desejo do sujeito" (Lacan, 1958-1959/2016, p. 444).

Lacan verifica que a interpretação da analista sobre a mãe fálica está correlacionada à contratransferência. E afirma: "Tudo leva a crer que a entidade da mãe fálica é produzida ali em razão daquilo que a autora chama de suas próprias posições contratransferenciais" (Lacan, 19561957/1995, p. 89). E questiona: "Por que a mãe fálica, quando se trata, realmente, do homem de armadura com todo seu caráter heráldico?" (Lacan, 1956-1957/1995, p. 89).

Aliás, o segundo sonho, da mulher com três pênis, que, na interpretação da analista, confirmaria sua hipótese da mãe fálica, aponta justamente para o contrário. Em seu texto "A cabeça de Medusa", Freud (1940 [1922]/2006, p. 289) nos diz:

Os cabelos na cabeça da Medusa são frequentemente representados nas obras de arte sob a forma de serpentes e estas, mais uma vez, derivamse do complexo de castração. Constitui fato digno de nota que, por assustadoras que possam ser em si mesmas, na realidade, porém, 
servem como mitigação do horror, por substituírem o pênis, cuja ausência é a causa do horror. Isso é uma confirmação da regra técnica segundo a qual uma multiplicação de símbolos de pênis significa castração.

Cabe lembrar que foi após as interpretações da analista que Yves começou a ter reações que manifestam uma certa aproximação da distância do objeto real, como espiar as pernas da analista - o que ela nota, inclusive, com uma certa satisfação.

Segundo Lacan:

Existe aí, com efeito, algo que está na borda da situação real, como se assistíssemos à constituição da mãe, não fálica, mas afálica. $O$ que está, de fato, no princípio da instituição da posição fetichista é, muito precisamente, o fato de que o sujeito se detém num certo nível de sua investigação e de sua observação da mulher, na medida em que ela tem ou não tem o órgão posto em questão. (Lacan, 1956-1957/1995, p. 90)

O que Lebovici chama de "perversão transitória" é, segundo Lacan, uma "reação perversa desencadeada", que "apareceu em circunstâncias bem precisas, de que [a analista] participou" (Lacan, 1956-1957/1995, p. 89). O ponto crucial, evidenciado no desenrolar de todo o quadro clínico, relaciona-se a uma fantasia "interpretada em termos de realidade, como uma experiência real da mãe fálica" (Lacan, 1958-1959/2016, p. 444).

"A contribuição do deciframento é realmente mínima", comenta Lacan, "a ponto de nos perguntarmos se sua maior parte não permanece intacta no enquistamento do enigma que, sob o rótulo de perversão transitória, é objeto dessa intrusiva comunicação" (Lacan, 1958/1998, p. 617).

Em O Seminário, livro 9: a identificação, Lacan (1961-1962, lição de 06/06/62) enuncia a seguinte proposição: "a interpretação deve incidir sobre a causa do desejo", chamando a atenção para o fato de que incidir sobre a causa de desejo não significa responder com um saber sobre o objeto, nomeando-o. Como por exemplo, se um analista dissesse a um obsessivo: "você é como merda". Pois, ao nomear o objeto fezes, o analista aponta o objeto a partir do saber, fazendo consolidar a fantasia. Este exemplo de Lacan cai como uma luva no caso apresentado por Ruth Lebovici, na medida em que ela, ao injetar seus próprios significantes, consolida a fantasia, reforçado os sintomas do seu analisante.

Ao chamar atenção para o fato de que "interpretação incide sobre a causa do desejo", Lacan procura alertar que a interpretação deve se ater ao objeto causa de desejo, na medida em que, certamente, a interpretação concerne ao objeto, mas não para falar dele, mas para esvaziálo. A interpretação deve operar no nível da falha do saber suposto, fazendo surgir uma questão, 
efeito inverso ao de dar uma resposta.

Pode-se verificar que Lebovici, em sua ambição terapêutica, "cometeu o erro de se permitir brincar com o desejo do sujeito, como se se tratasse do que, nele, devesse ser posto no devido lugar" (Lacan, 1958-1959/2016, p. 444). Ao conduzir uma análise no limite entre a análise e a reeducação, a analista ilustra o que Freud nomeia como "psicanálise selvagem", na medida em que ela interpreta como uma "perversão transitória" o que seria, na verdade, um acting out dirigido a ela própria.

\section{Referências Bibliográficas}

Freud, S. (2006). A interpretação dos sonhos. Tradução de Renato Zwick. Porto Alegre: L\&PM Editores, 2016. (Trabalho original publicado em 1900).

Freud, S. (2006). Psicanálise selvagem. Edição standard brasileira das obras psicológicas completas de Sigmund Freud (v. XI). Rio de Janeiro: Imago. (Trabalho original publicado em 1910).

Freud, S. (2006). A cabeça de Medusa. Edição standard brasileira das obras psicológicas completas de Sigmund Freud (v. XVIII). Rio de Janeiro: Imago (Trabalho original publicado em 1940[1922]).

Lacan, J. (1995). O Seminário, livro 4: a relação de objeto, 1956-1957. Rio de Janeiro: Jorge Zahar Ed.

Lacan, J. (1998). A direção do tratamento e os princípios de seu poder. Escritos. Rio de Janeiro: Jorge Zahar Ed. (Trabalho original publicado em 1958).

Lacan, J. (1999). O Seminário, livro 5: as formações do inconsciente, 1957-1958. Rio de Janeiro: Jorge Zahar Ed.

Lacan, J. (2016). O Seminário, livro 6: O desejo e sua interpretação, 1958-1959. Rio de Janeiro: Jorge Zahar Ed.

Lacan, J. (Inédito). O Seminário, livro 9: a identificação, 1961-1962.

Lacan, J. (2008). O Seminário, livro 16: De um Outro ao outro, 1968-1969. Rio de Janeiro: Jorge Zahar Ed.

Lebovici, R. (1999). Perversão sexual transitória no decorrer de um tratamento analítico. Hans ea fobia. Rio de Janeiro: Escola da Letra Freudiana. (Trabalho original publicado em 1956). 
Citacão/Citation: Loures, J.M.T.; Martinho, M.H. (mai. 2018 a out. 2018). Psicanálise Selvagem ou Perversão transitória? Revista aSEPHallus de Orientação Lacaniana, 13(26), 126-133. Disponível em www.isepol.com/asephallus. Doi: 10.17852/1809-709x.2019v13n26p126-133.

Editor do artigo: Tania Coelho dos Santos.

Recebido/Received: 03/01/2019 / 01/03/2019.

Aceito/Accepted: 12/03/2019 / 03/12/2019.

Copyright: (C) 2019 Associação Núcleo Sephora de Pesquisa sobre o moderno e o contemporâneo. Este é um artigo de livre acesso, que permite uso irrestrito, distribuição e reprodução em qualquer meio, desde que o autor e a fonte sejam citados/This is an open-access article, which permites unrestricted use, distribution, and reproduction in any medium, provided the author and source are credited. 